\title{
Impact of Allogrooming in Domestic Cats (Felis silvestris catus) on Mitochondrial DNA Profiling of Shed Hairs
}

\author{
Robert A. Grahn*, Tina I-T Huang and Leslie A. Lyons
}

Department of Population Health \& Reproduction, School of Veterinary Medicine, University of California, Davis, Davis, CA 95616, USA

\begin{abstract}
Allogrooming is a normal behavior for socially bonded cats. Cat hairs may have epithelial cells on the shaft from at least two cat contributors, the host (groomee) and the donor (groomer). To determine the likelihood of obtaining a mixture or incorrect DNA profile in cat hairs, feline mtDNA control region from hairs of allogrooming cats was isolated and analyzed by direct sequencing. Two DNA extraction methods were tested; hair washes and complete digestion of hairs. For five allogrooming pairs with different mitotypes, thirteen of the 126 sequences $(10.3 \%)$ matched the mitotype of the groomer, not the groomee. Forty-three sequences (34.13\%) suggested the presence of both mitotypes, groomer and groomee. Approximately $2.4 \%$ of mtDNA sequences appeared heteroplasmic at mitotype defining sites. Heteroplasmy was not observed in 157 control sequences. Mitotypes from the groomer was 11-fold more difficult to obtain from hairs that were completely digested before DNA isolation and was not observed in samples if the hairs were washed prior to digestion. Unlike contamination issues in human forensic cases, obtaining more than one mtDNA profile from a feline hair sample could narrow the pool of suspects since the implicated cat(s) would have to be within the same vicinity and have social contact.
\end{abstract}

Keywords: Forensic science, control region, heteroplasmy, feline, mitochondrial DNA, mitotype.

\section{INTRODUCTION}

According to the 2011-2012 National Pet Owners Survey [1], 38.9 million households own a cat accounting for 86.4 million cats in the United States. Cat hairs are readily transferred from pet to person, object to person and even person to person, during everyday activities, such as grooming, petting, or simply coming into contact with clothing or furniture. Locard's exchange principle states that when two items come into contact with each other, there is an exchange of materials [2] thus when an individual enters the home of a pet owner, the likelihood of leaving the house with hairs from that pet is very high. D'Andrea et al. (1998) demonstrated that during criminal activity, a perpetrator is unlikely to leave the house of a pet owner without inadvertently taking some pet hair [3].

Cat fur is composed of different hair types. Generally, cats have a longer thick, top guard hair layer and two layers of shorter and thinner, more abundant undercoat of awn and down fur [4]. The majority of a cat's coat and the majority of shed hairs are from the undercoat. Although cats do have more pronounced seasonal shedding in the spring and fall, cats shed hairs throughout the year with each individual hair having its own growth cycle [5]. For forensic purposes, microscopic analysis is typically limited to the guard hairs that contain species-specific diagnostic features. However,

*Address correspondence to this author at the 980 Old Davis Rd, Veterinary Genetics Laboratory, School of Veterinary Medicine, University of California - Davis, Davis, CA 95616, USA; Tel: 530-752-2314;

Fax: 530-752-3556; E-mail: ragrahn@ucdavis.edu all cat hairs are a potential source for DNA and therefore a means of individual identification.

Cats spend $8 \%$ of their waking hours licking their fur to maintain coat quality by removing ectoparasites [6], dirt, and stale oil [7]. Mother cats frequently groom their young to keep them clean. Additionally, cats that are related, mate with each other or cohabitate will often groom each other [8]. The common name for cat to cat licking is social grooming, or allogrooming. There is no differentiation between sexes for allogrooming with both males and females equally likely to groom either sex. During grooming, buccal cells in the saliva may be transferred to the hair shaft. Thus, cat hair found at a crime scene may actually have epithelial cells on the hair shaft from two contributors; the host cat, the groomee, and the donor cat, the groomer.

Mitochondrial DNA (mtDNA) can be more reliably amplified from hairs than genomic DNA due to limited, degraded genomic DNA fragments found in hair shaft. However, successful amplification of small amplicons has been demonstrated $[9,10]$. Reference mtDNA genome sequences are available for a variety of species [11-20] including the domestic cat [21]. The cat mtDNA control region (CR) has been shown to be effective in forensic diagnostics and a DNA sequence database is available for comparison [22-25]. Using direct sequencing to mimic field sample analysis, the frequency of cross-cat DNA transfer to hairs due to allogrooming was investigated under optimal circumstances. The sensitivity of the laboratory methods used for detection of allogrooming was also evaluated. 


\section{MATERIALS AND METHODOLOGY}

\section{Animals}

Thirteen socially bonded domestic cats (Felis silvestris catus) were evaluated for detectable DNA transfer during allogrooming behavior. Ten cats were from the University of California - Davis Feline Genetics Research Colony and three random bred cats were privately owned. Over the course of one month, allogrooming hair samples were collected from the 13 cats, some of which were used in more than one pairing, yielding nine allogrooming pairings (Table 1).

Table 1. Cat Pairings for Allogrooming mtDNA Analysis

\begin{tabular}{|c|c|c|c|c|}
\hline Cat & Lab ID & Groomer or Groomee & Mitotype & Pairing \\
\hline 1 & 4445 & Groomer & B & I \\
\hline 2 & 8638 & Groomer & B & II \\
\hline 3 & 5338 & $\begin{array}{l}\text { Groomer } \\
\text { Groomer }\end{array}$ & B & $\begin{array}{c}\text { III } \\
\text { VIII* }\end{array}$ \\
\hline 4 & 8637 & Groomer & B & IV \\
\hline 5 & 11286 & $\begin{array}{l}\text { Groomer } \\
\text { Groomee }\end{array}$ & $\mathrm{C}$ & $\begin{array}{l}\mathrm{V}^{*} \\
\mathrm{VI}^{*}\end{array}$ \\
\hline 6 & 11288 & $\begin{array}{l}\text { Groomer } \\
\text { Groomee }\end{array}$ & B & $\begin{array}{l}\text { VI* } \\
\text { VII* }\end{array}$ \\
\hline 7 & 9969 & Groomee & B & $\mathrm{IX}^{*}$ \\
\hline 8 & 9890 & $\begin{array}{l}\text { Groomee } \\
\text { Groomer }\end{array}$ & G & $\begin{array}{l}\text { VIII* } \\
\text { IX }^{*}\end{array}$ \\
\hline 9 & 8639 & Groomee & B & I \\
\hline 10 & 5072 & Groomee & B & II \\
\hline 11 & 10699 & Groomee & B & III \\
\hline 12 & 9712 & Groomee & B & IV \\
\hline 13 & 11287 & $\begin{array}{l}\text { Groomee } \\
\text { Groomer }\end{array}$ & A & $\begin{array}{c}\mathrm{V}^{*} \\
\mathrm{VII} *\end{array}$ \\
\hline
\end{tabular}

*The mtDNA mitotypes are different in five cat pairings (V - IX).

\section{Reference DNA Sample Collection \& Extraction}

Buccal reference samples were collected from each cat with sterile cytology brushes (Fisher Healthcare, Houston, TX). DNA was isolated using the QIAamp ${ }^{\circledR}$ DNA Mini Kit buccal swab protocol (Qiagen, Valencia, CA). Total DNA concentrations from buccal swab isolations ranged from 2 $\mathrm{ng} / \mu \mathrm{l}-19 \mathrm{ng} / \mu \mathrm{l}$ as determined using a NanoDrop ND-1000 Spectrophotometer (NanoDrop Technologies, Inc., Wilmington, DE). To confirm the transfer of sufficient DNA for isolation from a licked surface, cats were presented wet cat food (BABYCAT INSTINCTIVE, Royal Canin Inc., St. Charles, MO) on plastic spoons. After the food was consumed, the licked spoons were air dried and placed in labeled envelopes at room temperature. Within eight days, the surface of the spoons was wiped with phosphate buffered saline moistened Q-tips (Johnson \& Johnson, Langhorne, PA) to liberate transferred buccal cells. DNA was isolated from the Q-tips using QIAamp ${ }^{\circledR}$ DNA Mini Kit - buccal swab protocol (Qiagen, Valencia, CA).
To determine the detection limit of mixed mtDNA mitotypes by direct sequencing, reference DNA samples from three cats with mitotypes $\mathrm{A}, \mathrm{B}$ and $\mathrm{C}$ were quantified by qPCR using the Applied Biosytems 7300 Real Time PCR system (Applied Biosystems, Foster City, CA) and dilution mixtures were constructed in the following ratios: $1: 1,1: 2.5$, $1: 5,1: 10,1: 25,1: 50,1: 100,1: 250,1: 500$, and 1:1000. A total of five ng of template DNA was used in each PCR reaction at the listed major and minor component ratios. Reciprocal dilutions were performed to determine if directional dilution bias existed. Each dilution series was tested with four replicates.

\section{Allogrooming Hair Sample DNA Extraction}

When social allogrooming of co-housed cats was observed, hair was immediately cut with clean scissors close to, but not including, the root at the grooming site. Clipped hairs, which included all three hair types, were then placed in individual paper envelopes and sealed with tape. Total DNA was isolated from 20 non-washed individual hairs from each sample using the QIAamp ${ }^{\circledR}$ DNA Mini Kit - buccal swab protocol (Qiagen, Valencia, CA). This technique does not fully digest the hair. Extracted total DNA was stored at $4^{\circ} \mathrm{C}$.

\section{Hair Digestion Protocol}

Twenty hairs from three cat pairings (Table 1, pairs V-VII) were fully digested for DNA isolation. For each pairing, 10 hairs were washed to remove potential DNA from the external surface and 10 hairs were unwashed. For the washed hairs, each hair was inverted for 2 hrs in TE buffer to liberate any external cells and transferred to a clean tube for digestion. Each washed and unwashed hair was placed in an individual $1.5 \mathrm{ml}$ Eppendorf tube containing $200 \mu \mathrm{l}$ of digestion buffer (0.039 M DTT, $0.1 \mathrm{M} \mathrm{NaCl}, 50 \mu \mathrm{g} / \mathrm{ml}$ Proteinase K, 2\% SDS, and $0.003 \mathrm{M} \mathrm{CaCl}_{2}$ in TE (10mM Tris- $\mathrm{HCl}, \mathrm{pH} 8.0,1.0 \mathrm{mM}$ EDTA) and incubated with inversion at $56^{\circ} \mathrm{C}$ overnight. DNA was isolated by phenol:chloroform extraction using N-butanol for DNA precipitation [26]. Samples were purified and concentrated using Microcon Centrifugal Filter Devices YM100 (Millipore, Jaffrey, NH) following manufacturer's protocol with three additional distilled water rinses to ensure sample purity. Samples were eluted with $10-50 \mu \mathrm{TE}$ and stored at $-20^{\circ} \mathrm{C}$.

\section{PCR Amplification}

The mtDNA CR was amplified from the spoon derived DNA samples, the buccal swab DNA samples and the digested hair samples as previously described [25]. PCR amplification was performed on a PTC-200 DNA Engine (MJ Research, Waltham, MA). Each $20 \mu \mathrm{l}$ reaction mix contained $3 \mu 1$ of template DNA (6-60ng), $1.25 \mathrm{mM}$ dNTPs (Gen Script Corp., Piscataway, NJ), $1 \mu \mathrm{M}$ each of the forward and reverse primers (Operon Biotechnologies, Inc., Huntsville, AL), 2 mM $\mathrm{MgCl}_{2}, 1 \mathrm{X}$ PCR Buffer and 0.5 units Taq DNA polymerase (Denville Scientific Inc., Metuchen, NJ). PCR cycling conditions were as follows; $94^{\circ} \mathrm{C}$ for $3 \mathrm{~min}$ for denaturation, 35 cycles of $94^{\circ} \mathrm{C}$ for $1 \mathrm{~min}, 56^{\circ} \mathrm{C}$ for $30 \mathrm{sec}$, and $72^{\circ} \mathrm{C}$ for 45 sec, followed by a final extension at $72^{\circ} \mathrm{C}$ for $10 \mathrm{~min}$. Samples were stored at $4^{\circ} \mathrm{C}$ until further analysis. 


\section{mtDNA Sequencing and Analysis}

Mitochondrial DNA control region products were sequenced in both directions with published primers [25] using BigDye Terminator v3.1 cycle sequencing kit (Applied Biosystems, Foster city, CA) according to manufacturer's specifications on a 3730 DNA Analyzer (Applied Biosystems). These primers generate an amplicon avoiding NUMT background observed in some CR regions of the feline $\mathrm{mt}$ genome [21, 27]. Sequences were compared and evaluated using Sequencher 4.0 ${ }^{\mathrm{TM}}$ software (Gene Codes Corporation, Ann Arbor, MI). All sequences were trimmed and aligned using both Sequencher and Bioedit (Ibis Biosciences, Carlsbad, CA) programs to the $402 \mathrm{bp}$ "Sylvester" reference sequence of the cat mtDNA CR [22, 25]. Sequence sites with more than one nucleotide were identified and the sequences compared to a cat mtDNA database to determine the corresponding mitotype [22, 25]. The sequences generated from the hairs were compared to the reference sequence of each cat. Considering that the hair samples could be a mixture of mitotypes, consensus contigs were not constructed from the reverse and forward sequences, but compared independently to the reference sequence from the corresponding cat. Excluding areas where the sequence was aberrant, any sequence position with more than one nucleotide in the electropherogram was noted, regardless of amplitude.

\section{RESULTS}

\section{Baseline mtDNA Mitotypes}

Reference mtDNA sequences of 13 cats were generated from buccal swab DNA. Ten cats had the same sequence, mitotype B, for the 402 bp region. Three cats had mitotypes, A, C, or G (Table 1). The diagnostic sites between these mitotypes are presented in Table 2. Mitotype pair A - B has six variant sites, $A-C$ has nine variant sites, $B-C$ has three variant sites and $\mathrm{B}-\mathrm{G}$ has one variant site. Comparison of the mtDNA sequences of the 13 cats revealed that four of the nine allogrooming pairings had an identical sequence; thus, the detection of allogrooming could be observed in only five of the nine pairs (Table 1). The four pairings with identical mitotypes were used as "controls" for contamination and heteroplasmy evaluations (presented below). Mitochondrial DNA was successfully extracted and amplified from the licked spoons. The spoon DNA mitotypes were identical to the reference mitotypes derived from the buccal swabs (data not shown).

\section{Minimal Contribution Detection}

PCR amplicons were successfully generated and sequenced from a minimum of $5 \mathrm{pg} / \mu \mathrm{l}$ of every dilution mixture. To determine the minimal DNA contribution necessary to detect allogrooming using direct sequencing technology in the presence of a primary DNA source, reciprocal serial dilutions were established for the DNA from the cat pairings with mitotypes A-B. If an electropherogram peak was visible above baseline, regardless of relative amplitude, it was identified as a detected mixture (for example see Fig. 1C position 16895). Electropherogram scales were not adjusted to visualize minor peaks. All amplification and sequencing reactions were repeated to verify results. Mixtures were detected at all variant sites at the 1:5 dilution. Diagnostic differences between mtDNA sequences were consistently detected at the 1:50 dilution,

Table 2. Detection of Minor Component Mitotype by Direct Sequencing

\begin{tabular}{|c|c|c|c|c|c|c|c|}
\hline \multirow{3}{*}{ Dilution } & \multirow{2}{*}{$\begin{array}{c}\text { Mitotype } \\
\text { U20753 }\end{array}$} & \multicolumn{6}{|c|}{ Position } \\
\hline & & $16824 A$ & $16986 \mathrm{~T}$ & $63 \mathrm{~T}$ & 130T & $159 \mathrm{~T}$ & 173G \\
\hline & SRS & $11 \mathrm{~A}$ & $173 \mathrm{~T}$ & $260 \mathrm{~T}$ & $327 \mathrm{~T}$ & $356 \mathrm{~T}$ & 370G \\
\hline \multirow{2}{*}{$1: 1$} & A & + & + & + & + & + & + \\
\hline & B & + & + & + & + & + & + \\
\hline \multirow{2}{*}{$1: 2.5$} & A & + & + & + & + & + & + \\
\hline & B & + & + & + & + & + & + \\
\hline \multirow{2}{*}{$1: 5$} & A & + & + & + & + & + & + \\
\hline & $\mathrm{B}$ & + & + & + & + & + & + \\
\hline \multirow{2}{*}{$1: 10$} & $\mathrm{~A}$ & + & + & - & + & + & - \\
\hline & B & + & + & + & + & + & - \\
\hline \multirow{2}{*}{$1: 25$} & $\mathrm{~A}$ & + & + & - & + & + & - \\
\hline & B & + & + & - & + & + & - \\
\hline \multirow{2}{*}{$1: 50$} & $\mathrm{~A}$ & - & + & - & + & + & - \\
\hline & B & - & - & - & + & + & - \\
\hline \multirow{2}{*}{$1: 100$} & $\mathrm{~A}$ & - & - & - & + & - & - \\
\hline & B & - & - & - & - & - & - \\
\hline \multirow{2}{*}{$1: 250$} & $\mathrm{~A}$ & - & - & - & - & - & - \\
\hline & B & - & - & - & - & - & - \\
\hline
\end{tabular}


although not all possible sites were always observed. The minor component of a 1:100 dilution was detected in one sample, and only at one mitotype defining position. The sensitivity of sequencing data to reveal the minor component mitotype is presented in Table 2 .

\section{Allogrooming Detection}

Forty sequences were generated from non-washed hairs for the nine pairings $(\mathrm{N}=360)$, however 47 sequences $(13.06 \%)$ were excluded due to poor amplification. An additional 30 sequences were excluded in pairings XIII and IX due to poor sequence quality at the diagnostic sites. The remaining 283 sequences could be from the groomee, the groomer, or a mixture of both mitotypes. Four pairings (I IV) were between cats with the same mtDNA mitotype. There were no variable sites detected in these 157 sequences suggesting no heteroplasmy in this region in the control data set. Of the five pairings with different mitotypes, 13 of the 126 sequences $(10.32 \%)$ matched the mitotype of the groomer cat and the groomee mitotype was not observed (Table 3). Both mitotypes from a pairing were present in 43 $(34.13 \%)$ sequences. The remaining sequences ( $56 \%)$ matched the groomee mitotypes only (Table 3). A majority of samples with detectable mixtures showed significant differences in peak amplitudes (Fig. 1). As observed in the minimal mixture detection study, although mixtures at diagnostic mitotype sites were observed in 43 sequences, not every possible diagnostic site was detected (Fig. 1B vs 1C), particularly in the 17 samples representing pairing V - VII. In three mixture sequences $(2.4 \%)$, peak amplitudes of the two possible nucleotides at the variant sites were approximately equal, suggesting heteroplasmy rather than sample mixture. This observation was limited to pairings VIII and IX both having only one diagnostic site. Parenthetical numbers in Table $\mathbf{2}$ indicate observations of two nucleotides in the electropherogram in a contiguous sequence. For example, in pairing V (mitotypes A and C), the three sequences at position $16985 \mathrm{G}$ and the seven in $16986 \mathrm{~T}$ are all from the seven sequences listed as mixtures. The 36 representing the groomee showed no mixed sites. The chance of detection of allogrooming contamination from immediately isolated, unwashed cat hairs that have not been fully digested is $44 \%$.

\section{Hair Digestion Analysis}

DNA was obtained from 10 washed and 10 unwashed completely digested hairs for three pairings of cats with different mtDNA mitotypes (pairings V, VI and VII). For the

Table 3. Nucleotide Identity from Allogrooming Hair Samples

\begin{tabular}{|c|c|c|c|c|c|c|c|c|c|c|c|c|}
\hline Pairing & Source & Number & Type & \multicolumn{9}{|c|}{ Position } \\
\hline & $\mathrm{U} 20753$ & & & $16824 A$ & $16859 \mathrm{~T}$ & $16985 G$ & $16986 \mathrm{~T}$ & $59 \mathrm{~T}$ & $63 \mathrm{~T}$ & $130 \mathrm{~T}$ & $159 \mathrm{~T}$ & $173 G$ \\
\hline & SRS & & & $11 \mathrm{~A}$ & $46 \mathrm{C}$ & $172 A$ & $173 \mathrm{~T}$ & $255 \mathrm{C}$ & $260 \mathrm{~T}$ & $327 \mathrm{~T}$ & $356 \mathrm{~T}$ & $370 G$ \\
\hline & EU864495.1 & & A & A & $\mathrm{C}$ & A & $\mathrm{C}$ & $\mathrm{C}$ & $\mathrm{T}$ & $\mathrm{C}$ & $\mathrm{T}$ & A \\
\hline & EU864496.1 & & B & G & $\mathrm{C}$ & A & $\mathrm{T}$ & $\mathrm{C}$ & A & $\mathrm{T}$ & $\mathrm{C}$ & G \\
\hline & EU864497.1 & & $\mathrm{C}$ & $\mathrm{G}$ & $\mathrm{T}$ & $\mathrm{G}$ & $\mathrm{T}$ & $\mathrm{T}$ & A & $\mathrm{T}$ & $\mathrm{C}$ & $\mathrm{G}$ \\
\hline & EU864501.1 & & G & A & $\mathrm{C}$ & A & $\mathrm{T}$ & $\mathrm{C}$ & A & $\mathrm{T}$ & $\mathrm{C}$ & G \\
\hline I-IV & Groomee/r & 157 & B & $\mathrm{G}$ & $\mathrm{C}$ & A & $\mathrm{T}$ & $\mathrm{C}$ & $\mathrm{A}$ & $\mathrm{T}$ & $\mathrm{C}$ & $\mathrm{G}$ \\
\hline $\mathrm{V}$ & Groomee & 36 & A & A & $\mathrm{C}$ & A & $\mathrm{C}$ & $\mathrm{C}$ & $\mathrm{T}$ & $\mathrm{C}$ & $\mathrm{T}$ & A \\
\hline $\mathrm{V}$ & Groomer & 0 & $\mathrm{C}$ & $\mathrm{G}$ & $\mathrm{T}$ & $\mathrm{G}$ & $\mathrm{T}$ & $\mathrm{T}$ & A & $\mathrm{T}$ & $\mathrm{C}$ & $\mathrm{G}$ \\
\hline V & Mixture & 7 & $\mathrm{~A} / \mathrm{C}$ & ${ }^{*} \mathrm{G} / \mathrm{A}(3)$ & $\mathrm{C}$ & A/G (3) & $\mathrm{C} / \mathrm{T}(7)$ & $\mathrm{C} / \mathrm{T}(6)$ & T/A (7) & $\mathrm{C} / \mathrm{T}(6)$ & $\mathrm{T} / \mathrm{C}(7)$ & ${ }^{\#} \mathrm{~A} / \mathrm{G}(4)$ \\
\hline VI & Groomee & 36 & $\mathrm{C}$ & G & $\mathrm{T}$ & G & $\mathrm{T}$ & $\mathrm{T}$ & A & $\mathrm{T}$ & $\mathrm{C}$ & G \\
\hline VI & Groomer & 4 & B & G & $\mathrm{C}$ & A & $\mathrm{T}$ & $\mathrm{C}$ & A & $\mathrm{T}$ & $\mathrm{C}$ & G \\
\hline VI & Mixture & 0 & $\mathrm{C} / \mathrm{B}$ & G & $\mathrm{T} / \mathrm{C}(0)$ & G/A (0) & $\mathrm{T}$ & $\mathrm{T} / \mathrm{C}(0)$ & $\mathrm{A}$ & $\mathrm{T}$ & $\mathrm{C}$ & G \\
\hline VII & Groomee & 20 & B & $\mathrm{G}$ & $\mathrm{C}$ & A & $\mathrm{T}$ & $\mathrm{C}$ & A & $\mathrm{T}$ & $\mathrm{C}$ & G \\
\hline VII & Groomer & 5 & A & A & $\mathrm{C}$ & A & $\mathrm{C}$ & $\mathrm{C}$ & $\mathrm{T}$ & $\mathrm{C}$ & $\mathrm{T}$ & A \\
\hline VII & Mixture & 10 & $\mathrm{~B} / \mathrm{A}$ & G/A (4) & $\mathrm{C}$ & A & $\mathrm{T} / \mathrm{C}(10)$ & $\mathrm{C}$ & $\mathrm{A} / \mathrm{T}(6)$ & $\mathrm{T} / \mathrm{C}(6)$ & $\mathrm{C} / \mathrm{T}(0)$ & G/A (0) \\
\hline VIII & Groomee & 7 & A & $\mathrm{G}$ & $\mathrm{C}$ & A & $\mathrm{T}$ & $\mathrm{C}$ & A & $\mathrm{T}$ & $\mathrm{C}$ & $\mathrm{G}$ \\
\hline VIII & Groomer & 0 & G & A & $\mathrm{C}$ & A & $\mathrm{T}$ & $\mathrm{C}$ & A & $\mathrm{T}$ & $\mathrm{C}$ & G \\
\hline VIII & Mixture & 12 & $\mathrm{~A} / \mathrm{G}$ & G/A(12) & $\mathrm{C}$ & A & $\mathrm{T}$ & $\mathrm{C}$ & A & $\mathrm{T}$ & $\mathrm{C}$ & G \\
\hline IX & Groomee & 5 & $\mathrm{G}$ & A & $\mathrm{C}$ & A & $\mathrm{T}$ & $\mathrm{C}$ & A & $\mathrm{T}$ & $\mathrm{C}$ & $\mathrm{G}$ \\
\hline IX & Groomer & 3 & A & $\mathrm{G}$ & $\mathrm{C}$ & A & $\mathrm{T}$ & $\mathrm{C}$ & A & $\mathrm{T}$ & $\mathrm{C}$ & $\mathrm{G}$ \\
\hline IX & Mixture & 11 & G/A & $\mathrm{G} / \mathrm{A}(11)$ & $\mathrm{C}$ & A & $\mathrm{T}$ & $\mathrm{C}$ & $\mathrm{A}$ & $\mathrm{T}$ & $\mathrm{C}$ & $\mathrm{G}$ \\
\hline
\end{tabular}

*Four of seven mixture sequences failed to produce quality data at this position.

\#Three of seven mixture sequences failed to produce quality data at this position.

Parenthesis () indicate number of sequences scored with both nucleotides. 


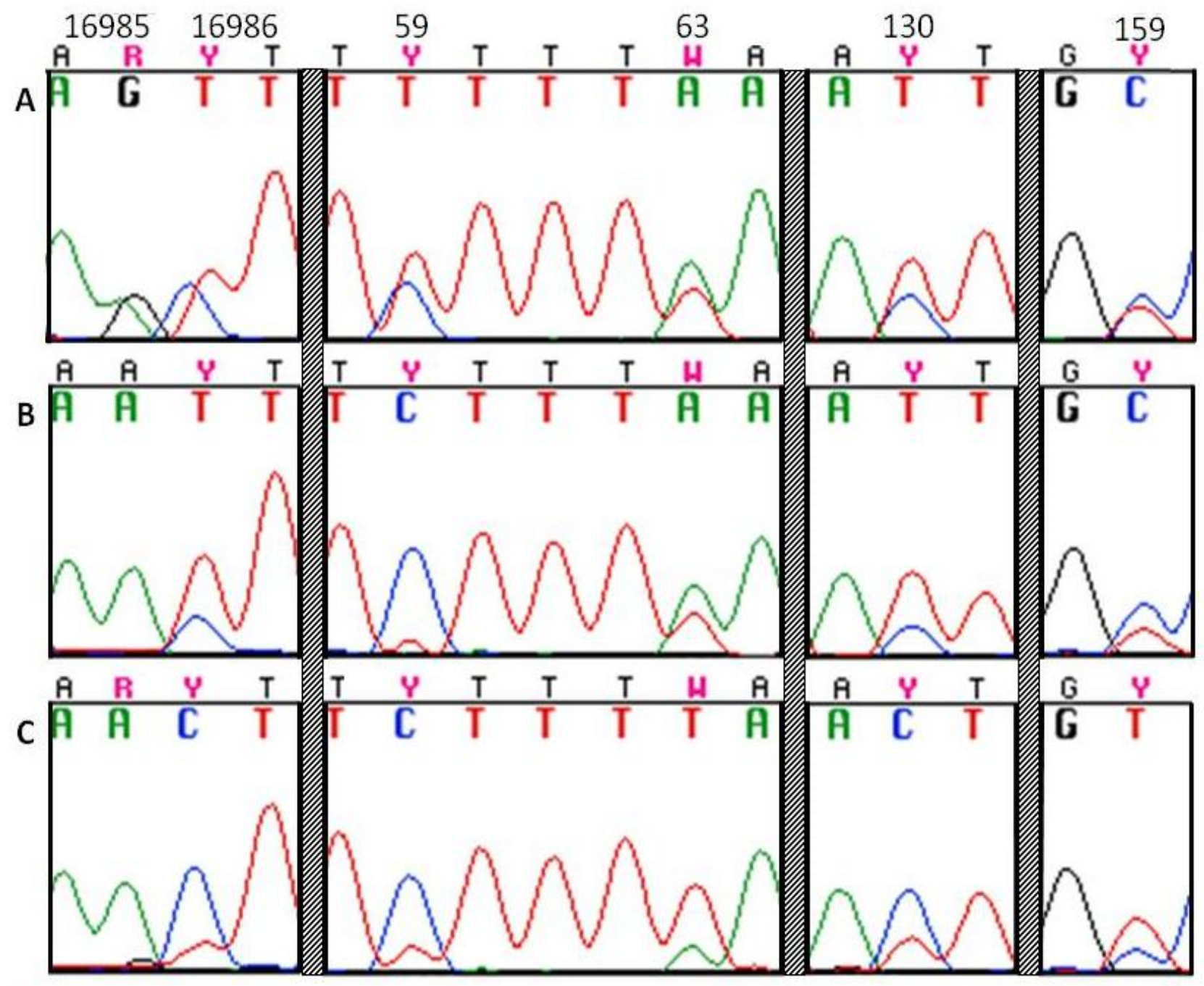

Fig. (1). Electropherogram data showing amplitude profiles at mitotype defining positions for two extractions of the same sample. A, B and $\mathrm{C}$ show contiguous electropherogram data with homologous stretches removed. Nucleotide positions relative to U20753 are provided at the top. A) 1:1 mix of a mitotypes A and C mixture sample. Variant site nucleotide amplitudes are approximately the same. B and C) A-groomee and C-groomer hair sample direct sequence data with differing peak profiles.

30 hairs washed prior to digestion, 51 of the 60 sequencing reactions generated passed quality control, including 16,19 , and 16 sequences from the respective pairings. All generated sequences matched the groomee only, showing no evidence of contamination. Fifty-four of the 60 sequences were successful for the unwashed hairs, including 15, 20, and 19 sequences from the respective pairings. Only pairing V contained two of 15 sequences that indicated a mixture of mitotypes (13.33\%). All other unwashed hairs had the groomee mitotype. For completely digested washed and unwashed hairs, the chance of detecting a mitotype mixture of allogrooming cats was $0.0 \%$ and $3.7 \%$, respectively.

\section{DISCUSSION}

Cat hair has had limited use as crime scene evidence, likely due to the lack of feline forensic expertise, limited feline population databases and the lack of knowledge of feline forensic resources. While the morphological traits of hair can provide insight into the nature of species and/or breed of the source animal [23], DNA isolated from the hair can help identify a specific individual by potentially providing STR, mtDNA and SNP profiles [28-31]. Just as Locard's Exchange Principle predicts transfer of evidence between sources, allogrooming can result in material transfer between cats, resulting in hairs covered with multiple DNA sources and potentially a mixture of DNA profiles.

DNA mixture profiles can suggest sample contamination, potentially leading to the dismissal of genetic forensic evidence. However, in the case of cat hair, multiple DNA sources could benefit an investigation as the "contamination by a second DNA source" may not be due to poor quality control or improper evidence handling. Multiple sources of cat DNA on cat hair can likely be a result of allogrooming [32]. DNA transfer can occur between cats during courtships, but mating is less frequent than allogrooming and a cat will likely remove any contaminating DNA from courtship during incessant self-grooming throughout the day [7]. For allogrooming DNA transfer to occur, cats must be familiar with one another, cohabitate, and/or live within the 
same limited territory. Approximately $30 \%$ of cat-owning households own more than one cat. Thus, the presence of two DNA sources on a cat's hair can actually narrow a suspect pool since two cats would need to be implicated and they would have required the opportunity to allogroom. This study examined the likelihood of detecting allogrooming under an ideal ascertainment scenario - immediately isolating the groomed hairs after witnessing allogrooming behavior.

To determine the limits of detection of the groomer mtDNA profile, serial dilutions of groomee $v s$ groomer DNA were evaluated. Using fluorescence-based direct sequencing techniques and standard PCR amplification protocols, allogrooming contamination was consistently detected when the groomee DNA was mixed with groomer DNA, up to a dilution of 1:50. Cat hair with DNA contribution from a groomer less than 1:50 requires more robust sequencing techniques to identify the contamination. Thus, natural variation in the amount of DNA source material transferred during allogrooming may significantly impact secondary source DNA detection.

When allogrooming occurs between cats, the cats' own grooming behavior will likely re-clean the allogroomed areas when anatomically possible. In this study, allogrooming was directly witnessed and groomed hairs were immediately cut, maximizing the potential for the detection of allogrooming contamination. Hair roots were not included in the analyses, mimicking shed hairs that are more likely to be found at a crime scene. Additionally, the inclusion of the root bulb would likely have overwhelmed the mixture with groomee DNA, obscuring the groomers DNA signature. In the allogrooming analysis, hairs were not digested and root bulbs were not included, thus, the analyzed DNA should have been derived from external epithelial cells on the hairs.

Cat allogrooming pairings included cats with and without the same mtDNA haplotype. Although a mixture study would potentially necessitate cloning of the DNA fragments to confirm the presence of two mitotypes, this study only used direct sequencing methods for several reasons. Firstly, cloning is not routine in casework, and the current study was designed to mimic forensic laboratory analyses in the detection of mixtures. Secondly, the mtDNA region analyzed does not contain a repeat sequence, thus, variation can be clearly identified by the presence of two nucleotides in a sequence. Thirdly, the level of detection and level of contamination from allogrooming was unknown, thus, extensive sequencing of clones may have been required to identify a second DNA source contribution especially considering successful amplification and sequencing of $5 \mathrm{pg}$ in the absence of a competing major template

The control pairings were used to estimate heteroplasmy and laboratory contamination. Twenty hairs were examined from each of four pairings of cats that had the same mtDNA haplotype. At least one forward and reverse sequence was generated for each replicate, resulting in 157 sequences. Considering the evaluations of only the major DNA source from the groomee, these four pairings did not show heteroplasmy or other sources of contamination based on a robust sampling of 20 individual hairs per cat. This data supports that the mtDNA CR region under analysis has low heteroplasmy (none observed in over 31,500 control base pairs sequenced in this study), even in tissues with a high mitotic index [33], such as hair.

Five pairings of cats included individuals with different mtDNA haplotypes. More than one mitotype was observed in $\sim 44 \%$ of sequences from hair samples removed from cross-groomed sites, identified by either mixture sequences or sequences of the groomer. Two peaks were only observed in electropherograms at mitotype defining positions. In three of the five pairings, $\sim 10 \%$ of the generated sequences represented the mtDNA mitotype of the groomer, while the groomee mitotype was not observed. These data suggest that the DNA extracted from the surface of a cat hair using the Qiagen extraction protocol can provide additional DNA typing information and has a high probability of detecting allogrooming if present but may also provide a cautionary warning regarding suspect searches derived from hair surface data.

Most standard operating procedures for hair analysis include washing the hair, followed by complete digestion prior to DNA extraction and analysis. An additional aspect of this study examined washed $v s$ unwashed hairs that were both digested to completion, all of which lacked hair bulbs. Of the 51 sequences generated from the 30 washed, digested hairs, none indicated that two different mtDNA profiles were present. Of 55 sequences from unwashed hairs, four sequences $(7.2 \%)$ - both forward and reverse sequences from two separate hairs - indicated a mixture. Thus, analysis of the wash itself may detect mixtures due to allogrooming more successfully than analysis of unwashed digested hairs and digestion of washed hairs yields mitotypes of the groomee only. However, sufficient replicates must be performed on the wash to confirm the identity and detection of mixtures, which may prove problematic with limited samples.

The digested hair evaluation demonstrates that mixtures can be detected even when groomee DNA is far more abundant than any transferred DNA. However, an electropherogram with two nucleotides at a site could be misinterpreted as heteroplasmy. The relative nucleotide amplitudes in electropherograms may suggest contamination $v s$ heteroplasmy. Although the ratio of any two mitotypes in a heteroplasmic individual is unknown, one might predict that both templates would be well represented resulting in base pair data points with similar amplitudes. Allogrooming DNA transfer would therefore appear as nucleotide peaks with lower amplitudes on the electropherogram. Only four sequences $(3.2 \%)$ suggested heteroplasmy based on relatively equal peak amplitude while the remainder, $\sim 31 \%$, appeared to be mixtures with low-level contamination. A single variable site would be more likely to represent heteroplasmy than multiple sites in one sequence. However, the likelihood of heteroplasmy being detected at a mitotype defining sites is expected to be no more likely than any of the other 401 positions under evaluation in this study. Between all currently known common cat mitotypes, nine sites are variable in the $402 \mathrm{bp}$ region. Hence, the recognition of a "heteroplasmic" site being at a site of variation between mitotypes is important to consider when reporting heteroplasmy $v s$ mixed DNA sources. In disproportionate mixtures, not all diagnostic sites were observed, possibly resulting from sequencing chemistry 
incorporation bias of adjacent nucleotides. Of true heteroplasmic sequences, the probability of just one heteroplasmic site occurring in the human mtDNA CR is roughly $10 \%$ [34-36]. One study suggested six heteroplasmic sites in a human mtDNA sequence, however these variations turned out to be sequencing errors [37, 38]. Thus, multiple site variation more likely represents sequencing errors or evidence of mixture. The location of observed variation should be considered especially when occurring at sites of known variants.

Four CR mtDNA mitotypes are common for cats in the USA and approximately $10 \%$ of cats are unique at the mtDNA CR [22]. Approximately $7.3 \%$ of a groomer and groomee combination would both have most common mitotype A, which is found in $\sim 27 \%$ of the USA population $(0.27 \times 0.27=0.073)$. Considering the cat mitotype frequencies from California, seven mitotypes account for $\sim 82 \%$ of the population, 25 mitotypes account for the remaining $18 \%$ of the population. Considering the seven pairings $(\mathrm{A}-\mathrm{A}, \mathrm{B}-\mathrm{B}, \mathrm{C}-\mathrm{C})$ that would have the same mitotypes, cats would have a probability of $17 \%$ to have the same mitotype, $83 \%$ having different mitotypes.

\section{CONCLUSIONS}

Hair mtDNA typing can be impacted by the grooming behaviors of cats. A surface licked by a cat provides adequate DNA for mtDNA analyses and the food off a spoon method introduced here can help crime scene investigators obtain DNA samples from fractious cats. Approximately $34 \%$ of the unwashed hair samples obtained from cat pairings that were known to have allogroomed showed the presence of more than one DNA source. The evaluation, through mtDNA analysis, of the wash liquid from a cat hair sample can add additional information to the mtDNA profile obtained and should be used to the advantage of criminal investigators. DNA extraction methods can impact the typing results that are obtained from hair samples. Unwashed hairs have the potential to carry more than one DNA source due to allogrooming, but following washing, digestion of the hair sample will provide the host mtDNA profile of the individual cat. Confusion between heteroplasmy and contamination, either in the laboratory or resulting from allogrooming, can be clarified by considering the number and positions of the nucleotide sites of mixtures in comparison to known cat mitotypes. In most forensics cases, the amount of evidence that is collected may not provide more than one or two replicates and suspected contamination may result in the exclusion of evidence. For the cat, a secondary DNA source mtDNA profile obtained from a hair wash may provide valuable additional data to implicate an appropriate suspect, albeit the cat, the owner, or a situation supporting hair transfer. Thus, in the cat, multiple DNA profiles from a DNA source may prove to be of added value to an investigation and warrants in-depth consideration.

\section{CONFLICT OF INTEREST}

The authors confirm that this article content has no conflict of interest.

\section{ACKNOWLEDGEMENTS}

Financial support was provided in part by National Institutes of Health - National Center for Research Resources (NCRR) grant R24 RR016094R24, now the Office of Research Infrastructure Programs (ORIP) grant R24OD010928, and the UC Davis Forensic Sciences graduate program. Laboratory assistance, training, and comments to the manuscript were provided by M.J. Lipinski, L.H. Bach, J.D. Kurushima, and M. Watters.

\section{REFERENCES}

[1] APPA National Pet Owners Survey. Greenwich, CT: American Pet Products Association, Inc.; 2012, pp. 1-593.

[2] Thornton, J.I.; Kimmel-Lake, D. Trace evidence in crime reconstruction. In: Crime Reconstruction. $1^{\text {st }}$ ed. Chisum W. J.; Turvey, B. E.; Eds. Elsevier Science \& Technology Books, Philadelphia: 2006, pp. 197-213.

[3] D'Andrea, F.; Fridez, F.; Coquoz, R. Preliminary experiments on the transfer of animal hair during simulated criminal behavior. $J$. For.Sci., 1998, 43(6), 1257-1258.

[4] Searle, A.G.; Jude, A.C. The 'Rex' type of coat in the domestic cat. J. Genet., 1956, 54(3), 506-512.

[5] WALTHAM. Skin and coat in cats. In: WALTHAM Course on Dog and Cat Nutrition. Edited by Grandjean D., Butterwick R. (online): Waltham Centre for Pet Nutrition; 1999, p. 18.

[6] Hart, B.L. Behavioral adaptations to pathogens and parasites - 5 Strategies. Neurosci. Biobehav. Rev., 1990, 14(3), 273-294.

[7] Eckstein, R.A.; Hart, B.L. The organization and control of grooming in cats. Appl. An. Beh. Sci., 2000, 68(2), 131-140.

[8] The signaling repertoire of the domestic cat and its undomesticated relatives. In: The domestic cat: the biology of its behaviour. Turner, D.C.; Bateson, P.; Eds. $2^{\text {nd }}$ ed. Cambridge University: Cambridge, 2000, pp. 76-87.

[9] Hellmann, A.; Rohleder, U.; Schmitter, H.; Wittig, M. STR typing of human telogen hairs--a new approach. Int. J. Legal Med., 2001, 114(4-5), 269-273.

[10] Muller, K.; Brugger, C.; Klein, R.; Miltner, E.; Reuther, F.; Wiegand, P. STR typing of hairs from domestic cats. For. Sci. Int. Genet. Sup. Ser., 2008, 1(1), 607-609.

[11] Anderson, S.; Bankier, A.T.; Barrell, B.G.; Debruijn, M.H.L.; Coulson, A.R.; Drouin, J.; Eperon, I.C.; Nierlich, D.P.; Roe, B.A.; Sanger, F.; Schreier P. H.; Smith A. J. H.; Staden R.; Young, I.G. Sequence and organization of the human mitochondrial genome. Nature, 1981, 290(5806), 457-465.

[12] Kim, K.S.; Lee, S.E.; Jeong, H.W.; Ha, J.H. The complete nucleotide sequence of the domestic dog (Canis familiaris) mitochondrial genome. Mol.Phyl.. Evol., 1998, 10(2), 210-220.

[13] Arnason, U.; Gullberg, A.; Janke, A.; Kullberg, M. Mitogenomic analyses of caniform relationships. Mol. Phylogenet. Evol., 2007, 45(3), 863-874.

[14] Hou, W.R.; Du, Y.J.; Chen, Y.; Wu, X.; Peng, Z.S.; Yang, J.; Zhou, C.Q. Nucleotide sequence of cDNA encoding the mitochondrial precursor protein of the ATPase inhibitor from the giant panda (Ailuropoda melanoleuca). DNA Cell Biol., 2007, 26(11), 799-802.

[15] Lin, C.S.; Sun, Y.L.; Liu, C.Y.; Yang, P.C.; Chang, L.C.; Cheng, I.C.; Mao, S. J.; Huang, M.C. Complete nucleotide sequence of pig (Sus scrofa) mitochondrial genome and dating evolutionary divergence within Artiodactyla. Gene, 1999, 236(1), 107-114.

[16] Park, Y.C. The complete mitochondrial genome sequence of the Amur leopard cat, Prionailurus bengalensis euptilurus. Mito. DNA, 2011, 22(4), 89-90.

[17] Wei, L.; Wu, X.; Zhu, L.; Jiang, Z. Mitogenomic analysis of the genus Panthera. Sci. China Life Sci., 2011, 54(10), 917-930.

[18] Willerslev, E.; Gilbert, M.T.; Binladen, J.; Ho, S.Y.; Campos, P.F.; Ratan, A.; Tomsho, L.P.; da Fonseca, R.R.; Sher, A.; Kuznetsova T.V.; Nowak-Kemp, M.; Roth, T.L.; Miller, W.; Schuster, S.C. Analysis of complete mitochondrial genomes from extinct and extant rhinoceroses reveals lack of phylogenetic resolution. $B M C$ Evol. Biol., 2009, 9(95), 1-11.

[19] Wu, G.S.; Yao, Y.G.; Qu, K.X.; Ding, Z.L.; Li, H.; Palanichamy, M.G.; Duan, Z.Y.; Li, N.; Chen, Y.S.; Zhang, Y.P. Population phylogenomic analysis of mitochondrial DNA in wild boars and domestic pigs revealed multiple domestication events in East Asia. Genome Biol., 2007, 8(11), 1-12. 
[20] Zhang, W.; Yue, B.; Wang, X.; Zhang, X.; Xie, Z.; Liu, N.; Fu, W.; Yuan, Y.; Chen, D.; Fu, D.; Zhao, B.; Yin, Y.; Yan, X.; Zhang, R.; Liu, J.; Li, M.; Tang, Y.; Hou, R.; Zhang, Z. Analysis of variable sites between two complete South China tiger (Panthera tigris amoyensis) mitochondrial genomes. Mol. Biol. Rep., 2011, 38(7), 4257-4264.

[21] Lopez, J.V.; Cevario, S.; Obrien, S.J. Complete nucleotide sequences of the domestic cat (Felis catus) mitochondrial genome and a transposed mtDNA tandem repeat (Numt) in the nuclear genome. Genomics, 1996, 33(2), 229-246.

[22] Grahn, R.A.; Kurushima, J.D.; Billings, N.C.; Grahn, J.C.; Halverson, J.L.; Hammer, E.; Ho, C.K.; Kun, T.J.; Levy, J.K.; Lipinski, M.J.; Mwenda, J.M.; Ozpinar, H.; Schuster, R.K.; Shoorijeh, S.J.; Tarditi, C.R.; Waly, N.E.; Wictum, E.J.; Lyons, L.A. Feline non-repetitive mitochondrial DNA control region database for forensic evidence. For. Sci. Int. Genet., 2011, 5(1), 3342.

[23] Halverson, J.L.; Basten, C. Forensic DNA identification of animalderived trace evidence: Tools for linking victims and suspects. Croat. Med. J., 2005, 46(4), 598-605.

[24] Halverson, J.L.; Lyons, L.A. Forensic DNA Identification of Feline Hairs: Casework and a Mitochondrial Database. Proc. Am. Acad. For.Sci., 2004, X, B150.

[25] Tarditi, C.R.; Grahn, R.A.; Evans, J.J.; Kurushima, J.D.; Lyons, L.A. Mitochondrial DNA sequencing of cat hair: an informative forensic tool. J. For. Sci., 2011, 56 (Suppl. 1), S36-46.

[26] Higuchi, R.; von Beroldingen, C.H.; Sensabaugh, G.F.; Erlich, H. A. DNA typing from single hairs. Nature, 1988, 332(6164), 543546.

[27] Goios, A.; Carvalho, A.; Amorim, A. Identifying NUMT contamination in mtDNA analyses. For. Sci. Int., Genet. Sup.Ser., 2009, 2(1), 278-280.

[28] Graham, E.A.M. DNA reviews: hair. For. Sci. Med. Pathol., 007, 3, 133-137.
[29] Bowling, A.T. Historical development and application of molecular genetic tests for horse identification and parentage control. Livestock Prod. Sci., 2001, 72(1-2), 111-116.

[30] Bender, K.; Schneider, P.M. Validation and casework testing of the BioPlex-11 for STR typing of telogen hair roots. For. Sci. Int., 2006, 161(1), 52-59.

[31] Muller, K.; Klein, R.; Miltner, E.; Wiegand, P. Improved STR typing of telogen hair root and hair shaft DNA. Electrophoresis, 2007, 28(16), 2835-2842.

[32] Crowell-Davis, S.L.; Curtis, T.M.; Knowles, R.J. Social organization in the cat: a modern understanding. J. Feline Med. Surg., 2004, 6(1), 19-28.

[33] Paneto, G.G.; Martins, J.A.; Longo, L.V.; Pereira, G.A.; Freschi, A.; Alvarenga, V.L.; Chen, B.; Oliveira, R.N.; Hirata, M.H.; Cicarelli, R.M. Heteroplasmy in hair: differences among hair and blood from the same individuals are still a matter of debate. For.Sci. Int., 2007, 173(2-3), 117-121.

[34] Brandstatter A.; Parson, W. Mitochondrial DNA heteroplasmy or artefacts - a matter of the amplification strategy? Int.J. Legal Med., 2003, 117(3), 180-184.

[35] Melton, T.; Dimick, G.; Higgins, B.; Lindstrom, L.; Nelson, K. Forensic mitochondrial DNA analysis of 691 casework hairs. $J$. For. Sci., 2005, 50(1), 73-80.

[36] Melton, T.; Nelson, K. Forensic Mitochondrial DNA Analysis: Two Years of Commercial Casework Experience in the United States. Croat.Med. J., 2001, 42(3), 298-303.

[37] Budowle, B.; Allard, M.W.; Wilson, M.R. Critique of interpretation of high levels of heteroplasmy in the human mitochondrial DNA hypervariable region I from hair. For.Sci. Int., 2002, 126(1), 30-33.

[38] Grzybowski, T. Extremely high levels of human mitochondrial DNA heteroplasmy in single hair roots. Electrophoresis, 2000, 21(5), 548-553.

Received: March 12, 2013

Revised: August 27, 2013

Accepted: September 11, 2013

(c) Grahn et al.; Licensee Bentham Open.

This is an open access article licensed under the terms of the Creative Commons Attribution Non-Commercial License (http://creativecommons.org/licenses/by$\mathrm{nc} / 3.0 /$ ) which permits unrestricted, non-commercial use, distribution and reproduction in any medium, provided the work is properly cited. 